\title{
AC 2007-124: SELF EFFICACY OF WOMEN ENGINEERING STUDENTS ? THREE YEARS OF DATA AT U.S. INSTITUTIONS
}

\section{Rose Marra, University of Missouri}

ROSE M. MARRA is an Associate Professor in the School of Information Science and Learning Technologies at the University of Missouri. She is PI of the NSF-funded Assessing Women and Men in Engineering (AWE) and Assessing Women In Student Environments (AWISE) projects. Her research interests include gender equity issues, the epistemological development of college students, and promoting meaningful learning in web-based environments.

\section{Barbara Bogue, Pennsylvania State University}

BARBARA BOGUE is Associate Professor of Engineering Science and Mechanics and Women in Engineering. She is co-PI of AWE and AWISE. Her research interests include recruitment and retention of women in engineering, assessment and career development.

\section{Kelly Rodgers, University of Missouri}

KELLY A. RODGERS, M. A. is a doctoral candidate in educational psychology at the University of Missouri - Columbia. Her research interests include motivational issues in minority student retention and the socio-emotional aspects of gifted minority adolescents.

\section{Demei Shen, University of Missouri}

DEMEI SHEN is a doctoral candidate in Information Science and Learning Technologies at the University of Missouri - Columbia. Her research interests include social computing and motivation in web-based learning. 


\title{
Self Efficacy of Women Engineering Students: Three Years of Data at U.S. Institutions
}

\begin{abstract}
This paper describes the results of three years of engineering self-efficacy data collected from engineering students at five institutions across the U.S. Results indicate that while students show positive progress on some self-efficacy and related subscales, they show a decrease on isolation subscale from the first to second measurement period. It is also notable that there are almost no gender differences and that self efficacy seems to be related to participation in extracurricular activities and student plans to persist in the degree.
\end{abstract}

\section{Background}

Self-efficacy has been found to be an important factor in the success of women studying engineering ${ }^{1,2}$.Although efficaciousness applies to any situation, it is particularly important in choosing and executing constructive actions in situations that are perceived as negative or a barrier to success (e.g. lack of a meaningful role in a team project). Given that women are generally under-represented in engineering classrooms, a strong sense of efficacy can help them to persist in such situations.

This paper reports on three years of engineering self-efficacy data collected from male and female engineering students at five institutions across the United States. The third year of data includes male respondents who are compared to their female counterparts. We measured selfefficacy via the LAESE survey instrument (longitudinal assessment of engineering self-efficacy; see AWEonline.org).

\section{Self-efficacy and Engineering Self-Efficacy}

Self-efficacy is an extensively researched psychological construct grounded in social cognitive theory. Self-efficacy, as defined by Albert Bandura ${ }^{3}$ "refers to beliefs in one's capabilities to organize and execute the courses of action required to produce given attainments" (Bandura ${ }^{4}$, p.3). Bandura ${ }^{3}$ claims that self-efficacy determines "the courses of action people choose to pursue, how much effort they put forth in given endeavors, how long they will persevere in the face of obstacles and failures, their resilience to adversity, whether their thought patterns are selfhindering or self-aiding, how much stress and depression they experience in coping with taxing environmental demands, and the level of accomplishments they realize.” (p. 3) In fact, a substantial amount of research is available to support these claims. Most relevant to women in engineering is the prolific research on self-efficacy beliefs in relation to academic achievement ${ }^{4}$ and to career choice ${ }^{6}$. The self-efficacy research literature makes a convincing case that a strong sense of self-efficacy is integral to all students' entry and persistence in engineering. Selfefficacy is hypothesized to come from four sources - two being more influential than the others. The most influential are mastery and vicarious experiences; social (including verbal) persuasion and physiological states (e.g. eliminating fear reactions can improve efficacy).

The term "self-efficacy" is often used interchangeably with several others, notably "confidence". Understanding the differences in these words is important in accurately interpreting the research 
literature and in developing programs or activities to influence self-efficacy, as well as accompanying assessment instruments. Confidence refers only to the strength of certainty of one's beliefs, but does not require a positive outcome-for example, a person may be absolutely confident in failure ${ }^{3}$. Although the term "confidence" is not synonymous with self-efficacy, it can be understood as a component of self-efficacy when expressed positively.

Literature about the experiences of women in engineering frequently addresses self-efficacy and its related constructs (e.g. confidence, self-esteem) showing a general pattern of loss emerges throughout the engineering education. Women enter engineering reporting high levels of selfconfidence and self-esteem ${ }^{7}$. Their self-confidence declines precipitously during the first year and, although it does begin to elevate, it will never again reach the same heights ${ }^{8}$. During this time, women compare themselves unfavorably to their male peers and judge themselves more harshly than the men judge themselves ${ }^{9}$. Women are aware of this and identify low selfconfidence as a major barrier to completing their engineering degree ${ }^{10}$. Women who leave engineering consistently express less confidence in their abilities than the men and women who stay, regardless of the fact that their actual performance is the same or better than their peers who do not leave ${ }^{8,11}$. The discouraging nature of low-self confidence is reflected in the fact that women faced with actually failing a course are likely to leave the engineering program altogether, while their male peers are more likely to repeat the course and continue to pursue their engineering degree.

While gender differences in "confidence" are often reported ${ }^{7}$, studies that examine gender differences in self-efficacy of students already enrolled in engineering programs show mixed results. In contrast to studies that did not find gender differences for engineering self efficacy or sources of efficacy ${ }^{12}$, several studies did find gender differences in self-efficacy of engineering students in relation to participants' perceived sources of self-efficacy. Bradburn ${ }^{13}$ found differences in self-efficacy among women and men, partially due to differences in negative persuasion (e.g. statements indicating that women can't do certain things) and anxiety signals. These differences were strong enough that, when the self-efficacy differences were eliminated statistically, gender differences in attrition were also eliminated. Zeldin and Pajares ${ }^{14}$ found gender differences in self-efficacy sources through their qualitative study of men and women who had entered into and continued to succeed in SMET professional careers. Narrative analysis revealed that men perceived mastery experiences as critical to their self-efficacy beliefs, while women valued verbal persuasion and vicarious experiences (e.g. experiencing a task or activity "second hand" through someone else's accomplishment of it).

Besterfield-Sacre ${ }^{15}$ used a validated instrument with first year engineering students that measured 13 attitudes - five of which can be classified as related to efficacy. Women exhibited lower scores on basic engineering skills and knowledge, problem solving ability and engineering abilities - although these self-reported ability measures results arelin conflict with actual measures of their ability and preparedness, which showed women did not differ from men on academic ability. Women showed higher scores on study habits for the first data collection in the study. Similarly, Grandy's ${ }^{16}$ study of SME seniors showed women with higher efficacy in two non-technical area skills-organizing work and time spent on homework. For the other eight measures in his study, men and women were quite similar. A recent mixed methods study from Hutchison et al. ${ }^{17}$ (2005) also found gender differences in sources of self-efficacy with 
substantial differences in how many men and women attributed computing abilities as either a positive or negative contributor to self-efficacy.

Highly validated instruments for self-efficacy have produced different results. Hackett et al.'s ${ }^{18}$ work examined SME vocational self-efficacy and academic milestones self-efficacy for 197 students and found no significant gender differences for either construct. Meinholdt and Murray's study ${ }^{19}$ was based on Hackett's instrument and found a trend $(p<.07)$ that favored men for academic self-efficacy but no gender differences for vocational self-efficacy.

Although researchers seem to agree that it is an important concept, the research results show a mixed view of gender differences for engineering self-efficacy. Further, these studies vary based on the degree of validation of the instruments used, the number of institutions examined (most were single institution), and overall there are few that gathered data from the same students more than once (Besterfield-Sacre ${ }^{15}$ is an exception). Given these results, this study uses a validated measure of engineering self-efficacy to women and male engineering students at five institutions and further analyzes the results based on pertinent sample characteristics: ethnicity, school and year in school. Further examination of self-efficacy differences by year standing are warranted given the prior pattern of "loss" in similar concepts such as confidence. Examining potential differences between schools is of interest in order to determine if certain schools demonstrate different patterns of self-efficacy trends, which may in turn be an indicator of differing climates that may either contribute or detract from self-efficacy. Lastly, prior research has shown that self-efficacy beliefs can vary by race and ethnicity ${ }^{20,21}$; thus additional exploration of this potential difference is warranted.

\section{Methods}

We collected data in the fall semester of 2003, 2004 and 2005 and analyzed data for two year changes in the 2003 to 2004 data set. LAESE was adjusted in 2005 based on prior results and thus those results can not be analyzed with the prior data. Cross sectional results are reported for the 2005 data set.

\section{Research Questions}

We explored the following research questions in our data analysis. Prior analysis ${ }^{22}$ has found several statistically reliable subscales in the LAESE instrument that are referred to in these questions.

1. Are there differences in 2003-2004 respondents (longitudinal) for the defined subscales for the overall data set? Do they vary by year in school, ethnicity, or institution?

2. Is there a relationship between students' self reported retention plans and their self-efficacy scores?

3. Are there gender differences for subscales, by institution, or by year-standing?

Subjects and Procedures 
Data from two sets of subjects are reported. One set for women who responded to both LAESE in both 2003 and 2004, and another set of men and women who responded to a revised LAESE in 2005.

There were 196 undergraduate women studying engineering at Penn State University, Georgia Institute of Technology, University of Texas-Austin, University of Arizona and the University of Louisville who responded to the LAESE_our self-efficacy survey instrument-in 2003 and then again in 2004. The five institutions for the subjects are all partner institutions in the NSF AWE grant and collectively represent a variety of private and public, years of experience for Women in Engineering (WIE) directors and student body characteristics that provide a women engineering student sample that is largely representative of undergraduate women studying engineering in the U.S. Table 1 shows the pertinent characteristics of each school.

\begin{tabular}{|l|l|l|l|l|}
\hline & $\begin{array}{l}\text { Institution } \\
\text { Enrollment }\end{array}$ & Eng. UG Enrollment & $\begin{array}{l}\text { Eng. \% Women } \\
\text { Undergraduates }\end{array}$ & WIE Established \\
\hline Penn State & 42,914 & 5,792 & 23.2 & 1989 \\
\hline UT - Austin & 36,878 & 4,536 & 21.5 & 1991 \\
\hline U. of Arizona & 28,368 & 2,684 & 18.6 & 1976 \\
\hline Georgia Tech & 11,841 & 6,453 & 28.2 & 2005 \\
\hline U. of Louisville & 11,347 & 1,151 & 14.7 & 1989 \\
\hline
\end{tabular}

Table 1. Institutional characteristics (source: Engineering Workforce Commission of American Association of Engineering Societies, 2006).

The distribution of our sample is shown in Table 2 by institution and year standing. The year standing data represent are for 2004 when respondents completed the self-efficacy instrument for the second time. There were 60 ethnic minorities in the sample (11 African Americans, 1 Native American, 27 Asians, 16 Hispanics, and 5 of some other ethnicity).

\begin{tabular}{|c|c|c|c|c|c|c|c|}
\hline & \multicolumn{6}{|c|}{ Academic year standing at $2^{\text {nd }}$ data collection: 2004} \\
\hline & & $\begin{array}{l}\text { First } \\
\text { Year }\end{array}$ & $\begin{array}{l}\text { Second } \\
\text { Year }\end{array}$ & $\begin{array}{l}\text { Third } \\
\text { Year }\end{array}$ & $\begin{array}{l}\text { Fourth } \\
\text { Year }\end{array}$ & $\begin{array}{l}\text { Fifth } \\
+\end{array}$ & Unknown \\
\hline Penn State & 40 & 0 & 9 & 11 & 15 & 5 & 0 \\
\hline UT-Austin & 89 & 0 & 33 & 23 & 24 & 9 & 0 \\
\hline $\begin{array}{l}\text { U. of } \\
\text { Arizona }\end{array}$ & 13 & 0 & 2 & 5 & 3 & 3 & 0 \\
\hline $\begin{array}{l}\text { Georgia } \\
\text { Tech }\end{array}$ & 39 & & 7 & 11 & 9 & 12 & 0 \\
\hline $\begin{array}{l}\text { U. of } \\
\text { Louisville }\end{array}$ & 15 & 1 & 4 & 4 & 0 & 6 & 0 \\
\hline Total & 196 & 1 & 55 & 54 & 51 & 35 & 0 \\
\hline
\end{tabular}

Table 2.Women respondents by institution and year at second data collection point (2004).

Subjects were contacted predominantly via email early in the fall 2003 and 2004 terms at each of the participating institutions and directed to a URL where they completed an online version of the instrument. The WIE programs sent the emails to all women students, whether they were 
affiliated with the WIE program or not. In fall 2004, special efforts were made to gather longitudinal responses from those who had completed the instrument in 2003. Of the initial 369 respondents who we expected to still be actively pursuing their degrees in fall 2004, we garnered the 164 subjects ( $44 \%$ of the original figure) reported analyzed for this paper. This response rate is in alignment with expectations for collecting longitudinal data ${ }^{23}$.

The authors revised LAESE before 2005 data collection in response to feedback from the participating institutions. Similar procedures were followed in fall 2005 however with this data collection the participating institutions (with the exception of Georgia Tech where data was not collected due to a change in priorities) solicited data from male and female students at all year standing levels. Again, targeted email invitations were sent to the female respondents who had completed the 2003 and / or 2004 instrument. However due to the changes in the instrument comparative analyses from these continuing respondents were not possible. Table 3 shows the total sample for 2005 by institution, year standing and gender. This sample was $47 \%$ male $(n=265)$ and 53\% $(n=295)$ female. This female representation is much higher than the general male / female ratio at these institutions due to intentional over sampling of women in order to have a large enough female sample for statistical analyses. Ethnicity information was gathered from 514 participants. There were 163 (31\%) ethnic minorities in the sample (29 African Americans, 1 Native American, 69 Asians, 43 Hispanic, and 21 of some other ethnicity).

\begin{tabular}{|c|c|c|c|c|c|c|c|c|c|}
\hline & \multicolumn{6}{|c|}{ Academic year standing } & \multirow[b]{2}{*}{ Total } & \multirow[b]{2}{*}{$\begin{array}{l}\text { Percentage } \\
\text { of sample }\end{array}$} \\
\hline & & $\begin{array}{l}\text { First } \\
\text { Year }\end{array}$ & $\begin{array}{l}\text { Second } \\
\text { Year }\end{array}$ & $\begin{array}{l}\text { Third } \\
\text { Year }\end{array}$ & $\begin{array}{l}\text { Fourth } \\
\text { Year }\end{array}$ & Fifth+ & Unknown & & \\
\hline \multirow{2}{*}{$\begin{array}{l}\text { Penn } \\
\text { State }\end{array}$} & Male & 43 & 23 & 26 & 30 & 10 & 0 & 134 & 23.6 \\
\hline & Female & 36 & 17 & 18 & 17 & 19 & 2 & 107 & 19.1 \\
\hline \multirow{2}{*}{$\begin{array}{l}\text { UT- } \\
\text { Austin }\end{array}$} & Male & 14 & 10 & 13 & 14 & 4 & 0 & 55 & 9.8 \\
\hline & Female & 30 & 27 & 18 & 11 & 9 & 0 & 95 & 16.7 \\
\hline \multirow[t]{2}{*}{ Arizona } & Male & 9 & 8 & 12 & 1 & 4 & 0 & 34 & 6.1 \\
\hline & Female & 21 & 5 & 9 & 7 & 8 & 0 & 50 & 8.9 \\
\hline \multirow[t]{2}{*}{ Louisville } & Male & 13 & 9 & 8 & 7 & 5 & 0 & 42 & 7.5 \\
\hline & Female & 12 & 7 & 13 & 9 & 2 & 0 & 43 & 7.7 \\
\hline \multicolumn{2}{|l|}{ Total } & 178 & 106 & 117 & 96 & 61 & 2 & 560 & -- \\
\hline \multicolumn{2}{|l|}{ Percentage } & 31.8 & 18.9 & 20.9 & 17.1 & 10.9 & .4 & -- & 100 \\
\hline
\end{tabular}

Table 3. Distribution of 2005 respondents by institution, year and gender.

\section{Instrument}

The LAESE (longitudinal assessment of engineering self-efficacy) instrument used in the study is a tested and validated survey designed to measure the self-efficacy of women studying engineering, feelings of inclusion and outcomes expectations ${ }^{2,22}$. Prior instrument development research has shown that self-efficacy is most validly measured by querying respondents about their feelings of efficaciousness in a very specific context; thus LAESE strives to measure engineering self-efficacy. To construct a self-efficacy instrument, one identifies the typical barriers that stand between the individual and her or his success in the domain. Thus, this self 
self-efficacy instrument is designed to identify the sources of barriers or obstacles in the task of obtaining an engineering degree and ascertain how capable a person feels in those situations. The survey, which includes original items as well as items adapted from Blaisdell ${ }^{1}$ and Betz and Hackett $^{6}$, was developed and pilot tested to ensure reliability and validity.

Results of our validity and reliability analyses showed that the survey measured several factors that are related to the concepts of self-efficacy, inclusion and outcomes expectations. Our statistical analyses showed acceptable Cronbach's Alpha reliability coefficients for each module; they ranged from .72 to .87 (see Figure 1). We ensured validity of our subscales with several procedures including factor analyses to ensure construct validity and external expert reviews to ensure content validity. These analyses resulted in six subscales that are listed in Figure 1.

\section{Subscales}

1. Engineering career expectations $(7$ items, alpha $=.84)$

2. Engineering self-efficacy I ( 5 items, alpha $=.82)$

3. Engineering self-efficacy II $(\underline{6 \text { items, alpha }=.82)}$

4. Feeling of inclusion (4 items, alpha $=.73)$

5. Efficacy in coping with difficulties $(\underline{6 \text { items, alpha }=.78)}$

6. Math outcomes efficacy $(3$ items, alpha $=.84)$

Figure 1. LAESE subscales.

Some sample items from the subscales are shown in Figure 2.

\section{Engineering Self Efficacy I and II}

\section{Sample Items}

(All scales: strongly disagree $(=0)$, to strongly agree $(=6)$ )

I can succeed in an engineering curriculum.

I can succeed in an engineering curriculum while not having to give up participation in my outside interests (e.g. extra curricular activities, family, sports).

Subscale: Feelings of Inclusion

I can relate to the people around me in my class.

I have a lot in common with the other students in my classes.

Figure 2. LAESE sample items.

The instrument also includes items on the respondents' participation in academic preparation activities, and their self-reported persistence in the degree plans. The instrument is best used as a longitudinal tool for all engineering undergraduate students annually at the beginning of the academic year. This longitudinal data collection combined with tracking of student participation in WIE activities and tracking for retention in the engineering curriculum will allow directors / researchers to ascertain the overall impact of different levels of participation or participation in specific activities on women's self efficacy in studying engineering. Further, if such tracking and data collection is done at a national level, the women in engineering community will have data for comparisons between and among different institutions and programs nationwide. 
Desirable outcomes from longitudinal data collection with LAESE would be an overall trend for an increase in subscale averages as a student progresses through the curriculum. This would indicate that her feelings of efficacy, ability to cope, etc. are increasing as they progress in their degrees.

\section{Results}

We examined the data to answer the following research questions that are pertinent to engineering education and underrepresented groups in particular:

To analyze the 2003 to 2004 data, we computed mean scores for each of subscales for the first and second data collection instances (e.g. fall 2003 and fall 2004) and applied the appropriate statistical analysis methods. We begin with the results for the 2003-2004 women engineering respondents.

1. Are there differences in 2003-2004 respondents for the defined subscales for the overall data set? Do they vary by year in school, ethnicity, or institution?

We found statistically significant differences using paired samples t-tests for four of the six subscales for respondents for the 2003 to 2004 data set. Coping strategies, self-efficacy II and math outcomes expectations subscales showed increased mean values from 2003 to 2004 ( $\mathrm{p}<$ .01 for all three); the feelings of inclusion subscale showed a decrease from 2003 to 2004 ( $\mathrm{p}<$ .05). ANOVA tests for the effect of institution, ethnicity and year standing did not show statistically significant differences.

2. Is there a relationship between students' self reported retention plans and their self-efficacy scores?

Respondents were asked in four different items to report their confidence level in being enrolled in their current engineering major next year, completing their current engineering major, completing any engineering major, or completing any degree at their current institution.

From 2003 to 2004, the women engineering student respondents' intention to persist in all four questions showed a statistically significant increase (all p values $<.032$ ). We also found strong correlations between the instrument subscales and responses to retention items. In 2003, there were statistically significant correlations with all subscales. The trend was very similar in 2004 with statistically significant correlations, again with the exception of subscale six and also subscale four (feelings of inclusion).

For the 2005 respondents there were also frequent correlations between the subscales and three of the four retention items. Subscales one, two, three, and five (career expectations, self-efficacy I \& II, coping self-efficacy) all showed statistically significant correlations $(\mathrm{p}<.05)$ with the three retention items that concerned persisting in engineering. The remaining item asked whether respondents thought they would complete any degree at the institution; this item was only significantly correlated with subscale three, engineering self-efficacy II. Subscales four (coping) and six (math outcomes expectations) were absent from the significant correlations for the 2005 data set. 
3. Are there gender differences for subscales, or cross sectional difference by institution, or by year-standing?

Lastly we report cross sectional results for self-efficacy subscales for the 2005 data. Analysis of variance revealed a significant effect for institution for subscales one (engineering outcomes expectations), and three (self-efficacy II) ( $\mathrm{p}<.05$ for all). Post-hoc analyses showed that, on subscale one, Penn State and University of Louisville scored higher than UT-Austin, and University of Arizona scored lower than all other institutions. University of Arizona also scored lower than all other institutions on subscale three. Additionally, there was a gender effect on subscale six (math outcomes), with women scoring higher than men $(\mathrm{p}<.05)$. Finally, a significant interaction between gender and institution was observed on subscales three and five. There were no significant differences for year in school.

\section{Discussion}

Our analysis revealed several noteworthy results both for the 2003-2004 data as well as for the cross sectional analysis of the 2005 sample. We discuss each in terms of implications for engineering support programs and curricula; future data collection; and analysis needed to further explore each result. We begin with the subscale main effects for the 2003-2004 data.

For the overall 2003 - 2004 data set, we saw significant gains for coping self efficacy, the second engineering efficacy scale, and math outcomes expectations and a negative change in scores for feelings of inclusion. We refer readers to Table 4 that shows the means for each subscale for 2003 and 2004 as well as the change in each subscale mean from 03 to 04 . The minimum and maximum values for items in each subscale are shown in parentheses after the subscale name.

The results for both coping and the second engineering self-efficacy scales can be considered positive. The items in the coping subscale indicate that students feel more competent in being able to take positive actions to cope with potentially difficult or barrier situations such as doing poorly on an exam or adjusting to a new campus environment. Further, the second engineering subscale asks students about their confidence in completing required portions of an engineering degree (e.g. "I am confident I can complete the physics requirements for an engineering major") and once again, student cohort indicated an increased confidence level in the 2004 results over the 2003. In contrast, the first self-efficacy subscale showed a slight decrease from time 1 to time 2 , although the decrease was not statistically significant. These subscale items are phrased differently than the $2^{\text {nd }}$ self efficacy scale_rather than saying "I am confident I can do ___ _, the subscale 1 items are phrased as "I can succeed (earn an A or B) in my engineering courses" (or math courses, or engineering curriculum). This can be interpreted as a stronger statement than the items in self-efficacy subscale 2, thus our results indicate a certain positive trend from subscale 2 but not so strong that the trend extends to the "succeed" statements in self-efficacy subscale 1 . The math outcomes scale also showed significant gains: this subscale only contains 3 items, however, and significantly, results indicated respondents show an increase in their perceptions of the potential benefit of learning and using mathematics in their careers. 


\begin{tabular}{|l|r|r|r|r|}
\hline Subscales (rating scale) & Mean 2003 & Mean 2004 & $\begin{array}{c}\text { Change } \\
(04-03)\end{array}$ & $\mathrm{N}$ \\
\hline $\begin{array}{l}\text { 1. Career Expectations } \\
(0-9)\end{array}$ & 6.39 & 6.32 & -.07 & 195 \\
\hline 2. Engineering Self- & 2.93 & 2.85 & -.08 & 194 \\
$\begin{array}{l}\text { Efficacy I (0-4) } \\
\text { 3. Engineering Self- } \\
\quad \text { Efficacy II (0-8) }\end{array}$ & 6.38 & 6.91 & .53 & 177 \\
4. Feelings of inclusion \\
$\begin{array}{l}\text { (0-4) } \\
\text { 5. Coping Self efficacy } \\
\text { (0-8) }\end{array}$ & 2.67 & 2.49 & -.18 & 195 \\
6. Math Expectations (0- \\
9)
\end{tabular}

Table 4. 2003-2004 Subscale Means

These increases in means are actually in contrast to prior self-efficacy research on women engineering students ${ }^{8,24}$. The differences in our results may be attributable to changes in the social psychological attributes of today's women engineering students - which is a hypothesis which must be further explored.

The negative trend in 2003-2004 respondents' sense of inclusion can be further understood by examining this subscale's means by respondent ethnicity. Table 5 shows these data for each ethnicity group for 2003 and 2004. The negative change from 2003 to 2004 for African American respondents $(\mathrm{n}=11)$ was greater (but not statistically significantly different) than other ethnicity groups (see Table 5). These results are important given the relatively small amount of research concerning self-efficacy and related beliefs of African Americans in an engineering context ${ }^{25}$. Other documentation of programmatic initiatives ${ }^{26}$ have indicated the need to address the relative isolation of African American students in engineering education, but formal research on this issue is needed to make a stronger case for programmatic and curricular changes. It is also important to note that all other ethnicity groups with the exception of AsianAmericans showed drops in inclusion from 2003 to 2004 although these drops were not as large as those seen for the African American sample. None the less, these results indicate that women engineering students, as a group across ethnicity, may perceive a sense of isolation in their studies.

For both the 2003-2004 data and the 2005 analysis we found very few identifiable differences in self-efficacy based on institution, school year, ethnicity or gender. The absence of these differences is important as well as it tells us that differences in self-efficacy are not being predictably impacted by these variables that we often hypothesize to promote differences in students and their academic success. Further it implies that the sources of self-efficacy defined in the social psychological theory (e.g. role models, vicarious experiences) are impacting these students in relatively the same way regardless of ethnicity, year in school and for the most part gender and institution. An exception in our data would be the University of Arizona where in the 2005 data we saw their students scoring significantly lower on the second self-efficacy scale. 


\begin{tabular}{|l|l|l|l|}
\hline & & \multicolumn{2}{|c|}{ Feelings of Inclusion } \\
Ethnicity & $\mathbf{N}$ & 2003 Mean & 2004 Mean \\
\hline $\begin{array}{l}\text { African/Black } \\
\text { American }\end{array}$ & 11 & 2.57 & 1.86 \\
\hline Native American & 1 & 2.0 & 1.5 \\
\hline Asian & 27 & 2.32 & 2.39 \\
\hline Latino/Hispanic & 16 & 2.56 & 2.31 \\
\hline Caucasian & 124 & 2.76 & 2.60 \\
\hline Other & 5 & 2.95 & 3.05 \\
\hline
\end{tabular}

Table 5. 2003-2004 Inclusion Subscale by Ethnicity.

For instance, the lack of significant differences by year in school is an initial indication that, overall, students are not reporting a pattern of increasing feelings of efficacy (for example) as they progress through the curriculum. If we had seen such a trend, we may have been able to conclude that students are feeling "better" about the factors measured by the subscales—but this was not the case.

This lack of self-efficacy growth is in alignment with prior results from both Brainard and Carlin ${ }^{8}$ and Felder et al. ${ }^{24}$. In a longitudinal study of Chemical Engineering students, Felder and his colleagues found several differences between male and female students including, that the expectations of female students about their performance in engineering dropped as they proceeded through the curriculum and they also reported lower levels of basic problem solving ability than men - even though the female students began their studies exhibiting equal levels of academic ability as their male counterparts.

Although both studies show that women students' self reported levels of confidence, ability or expectations dropped as they proceeded through the curriculum, Brainard and Carlin ${ }^{8}$ specifically show that levels of confidence in academic abilities in math and science drop from the beginning of the first year through junior years and then begin to rise again at the end of the senior year but never regain their initial levels.

We recognize the need to analyze more gender-comparative data. The lack of a pattern of selfefficacy differences by gender in the 2005 data set-recall that the only difference we found by gender was for the math outcomes self-efficacy subscale-is in alignment with the mixed gender results found in prior studies. In his review of under-representation of women in engineering, Malicky ${ }^{27}$ examined the results of gender-based self-efficacy research and concluded that results from the validated instruments showed very few gender differences with only the study from Besterfield-Sacre ${ }^{15}$ showing differences in contrast to studies from Hackett ${ }^{18}$, Schaefers ${ }^{12}$ and Meinholdt ${ }^{19}$ that do not.

The relationship of self-efficacy to other indicators in the LAESE instrument was particularly noteworthy. We found relationships between student intentions to persist in the degree, their participation in extra-curricular activities and satisfaction in the degree. For both data sets we found that students' self-reported intention to persist in their engineering degrees was positively related to nearly all the subscales - the consistent exception being the math outcomes scale. Our 
analyses can not distinguish whether better self-efficacy is influencing students' persistence intentions, if intention to persist influences self-efficacy, or whether the two simply co-exist. We are in the process of tracking actual retention behaviors with these samples, however our current results that show a relationship between retention and self-efficacy are consistent with several multi- and single institution studies that found that relationships (sometimes predictive) between retention and either self-efficacy or related measures ${ }^{8,12,28}$.

\section{Implications, Conclusions and Further Research}

Why is it worthwhile to study self-efficacy? Results from reliable self-efficacy measures can identify factors in retention and success in the engineering curriculum, which in turn can underpin design of activities to increase retention and success. And just as important, because there is some evidence from prior studies that self-efficacy may contribute to differences in success for women and minority students. Given these motivations, the results of these data can be used to inform engineering education practice - both in and outside of the classroom.

The results of this study show that there were longitudinal "positive" statistically significant differences for the coping, mathematics, and the second self-efficacy subscales. There was also, notably, a significant negative difference for the isolation subscale. Although all ethnicity categories showed a drop in this subscale we note that African American respondents showed the greatest drop although it was not statistically significantly different from other groups. We found consistent and positive relationships between students' self-reported retention plans in engineering and nearly all of the self-efficacy scales for both sets of data. And in the 2005 data set we found very few cross sectional differences between respondents based on institution, and - notably - gender. The only gender difference was for the math outcomes expectations subscale where women had a higher mean than men. This is an important result as it indicates that the overall engineering education experience is impacting self-efficacy of men and women in similar ways. Future data collection efforts using LAESE will determine if the patterns we have found continue. The current results imply potential implications for engineering educators:

- Encourage/expand programs such as academic success seminars ${ }^{26}$ that target developing feelings of inclusion in minority students and have been linked to good academic performance and improved retention rates. Consider expanding/growing such programs to develop feelings of inclusion among students of different races, in contexts that are not specifically for minority students only. We note that our data does not tell us if the African American students in our sample were active participants in the minority engineering programs that are available at these institutions.

- All of the institutions in this study have Women in Engineering (WIE) programs and many of the student respondents participated in WIE activities. Prior student self-report results from the WECE study ${ }^{29}$ showed the positive impact of participation in WIE programs. The positive significant differences for the coping, mathematics and second self-efficacy scales are both in contrast to prior research ${ }^{8,24}$ and provide additional support for participation in WIE activities. Future analysis of our data will examine the relationship between all extra curricular activity participation and self-efficacy.

- Having said this, we did not see a trend of scale growth or significant cross sectional differences by school year, which would be a strong positive indication of students 
feeling more efficacious as they proceed through the degree. Our results, in this regard, are consistent with prior work from Brainard and Carlin ${ }^{8}$.

- As significant as the lack of cross-sectional differences by school year are our results that show very few gender differences in self-efficacy indicate that the curriculum over time is impacting male and female students' efficacy in similar ways. These results provide preliminary evidence that either curricula are not designed or are not being implemented in a way that can promote self-efficacy or that the existing curricular or extracurricular experiences impeded self-efficacy growth.

We cannot believe that either curricular or extra curricula activities are intentionally designed to negatively impact sources of self efficacy such as having positive mastery or even vicarious experiences but rather it seems more likely that somehow they are implemented in ways that may negatively impact or not promote growth in efficacy. This implies the need to examine self -efficacy in relationship to specific implementations of courses and activities. How do specific course and activity implementation strategies - or put differently - how does their climate - impact self-efficacy?

As is often the case, the results of one study engender the need for several other studies:

- Examine, perhaps via qualitative studies to supplement quantitative data, how African American students experience the engineering environment. Such work would need to document and test whether our current results hold true for both participants and non participants of minority engineering and other support programs. Expand these methods to all students as our data show that other student groups also do not experience positive growth in feeling connected to the engineering environment.

- Continue to examine gender comparative results by gathering and analyzing more data from male students with LAESE. Even though our data did not show a pattern of selfefficacy differences between men and women, women continue to be retained at lower levels than men in engineering ${ }^{30}$. Is efficacy not as strong a predictor of retention as previously thought or is some other dynamic at play?

- Correlate actual retention data with the students' self-reported retention plans and their self-efficacy data. We are in the process of gathering these data currently and may be able to report them at the conference.

- Utilize additional statistical methods to investigate causal or directional relationships. The study presented here uses largely ANOVA methods. However, integrating advanced statistical methods would provide an additional dimension to the study of self-efficacy and its correlates among engineering students. In this study, the six LAESE subscales were largely inter-correlated. Through statistical methods like structural equation modeling, directional relationships between the subscales may be determined. This would allow WIE and other such programs to identify points of intervention and consequently design more effective learning environments for women and minority students in engineering.

- At the beginning of this discussion, we made note of the mixed results in research that studied the effect of gender on the self-efficacy of engineering students (p. 2). Future research on the relationship between gender and self-efficacy should integrate qualitative methods. The mixed results may be due to confounding variables that may not have been previously considered. Qualitative methods like investigative interviewing may help to 
begin to uncover such variables that suppress or inflate an observed statistical relationship between engineering students' self-efficacy and gender.

This study examined changes in self-efficacy data for a cohort of women engineering students at five institutions over two years, the relationship between self-efficacy and self-reported retention plans and gender and institution differences for male and female engineering students. Past studies have shown the importance of efficacy in retaining engineering students. Our results are mixed with some subscales showing positive growth while others are negative, and notably, very few gender or institutional based differences in self-efficacy. Although further studies (including qualitative studies) are needed to better understand these results there are implications for both external support programs (e.g. WIE programs) as well as the need to understand how the curriculum impacts these results.

\section{References}

1. Blaisdell, Stephanie (2000). Social cognitive theory predictors of entry into engineering majors for high school students. Arizona State University. Unpublished dissertation.

2. Marra, R.M., Schuurman, M., Moore, C., \& Bogue, B. (2005). Women engineering students' self-efficacy beliefs - The longitudinal picture. Proceedings of the annual meeting of the American Society for Engineering Education Annual Conference, 12 - 15 June, Portland, OR.

3. Bandura, A. (1997). Self-Efficacy: The Exercise of Control. New York: W.H. Freeman and Company.

4. Bandura, A. (1986). Social foundations of thought and action: a social cognitive theory. Englewood Cliffs, N.J.: Prentice-Hall.

5. Lent, R., Brown, S. D., \& Larkin, K. (1986). Self-efficacy in the prediction of academic performance and perceived career options. Journal of Counseling Psychology, 33(3), 265-269.

6. Betz, N.E., \& Hackett, G. (1981). The relationship of career-related self-efficacy expectations to perceived career options in college women and men. Journal of Counseling Psychology, 28(5), 399-410.

7. O’Hare, S. (1995). Freshmen women in engineering: Comparison of their backgrounds, abilities, values, and goals with science and humanities majors. Journal of Women and Minorities in Science and Engineering, 2, 33-47.

8. Brainard, S., \& Carlin, L. (1998). A six-year longitudinal study of undergraduate women in engineering and science. Journal of Engineering Education, 87(4), 369-375.

9. Hawks, B. K., \& Spade, J. Z. (1998). Women and men engineering students: Anticipation of family and work roles. Journal of Engineering Education, 249-256.

10. Brainard, S.G. (1993). Student Ownership: The Key to Successful Intervention Programs. Initiatives, 55(3), 23-30.

11. Jackson, L. A., Gardner, P. D., \& Sullivan, L. A. (1993). Engineering persistence: Past, present, and future factors and gender differences. Higher Education, 26, 227-246.

12. Schaefers, K. G., Epperson, D.L. \& Nauta, M. M. (1997). Women's career development: Can theoretically derived variables predict persistence in engineering majors. Journal of Counseling Psychology, 44, 173 183. 
13. Bradburn, E.M. (1995). Engineering gender roles: A self-efficacy model of occupational choice and persistence. Dissertation Abstracts International Section A: The Humanities and Social Sciences 55(7) (January), 2146A.

14. Zeldin, A., \& Pajares, F. (2000). Against the odds: Self-efficacy beliefs of women in mathematical, scientific, and technical careers. American Educational Research Journal, 37(1), 215-246.

15. Besterfield-Sacre, M.B., Moreno, M., Shuman, L.J., \& Atman, C.J. (2001). Gender and ethnicity differences in freshman engineering student attitudes: A cross-institutional study. Journal of Engineering Education, 90, 477-490.

16. Grandy, J. (1997). Gender and ethnic differences in the experiences, achievements, and expectations of science and engineering majors. Journal of Women and Minorities in Science and Engineering, 3, 119-143.

17. Hutchison, M., Follman, D.K., Sumpter, M., \& Bodner, G.M. (2005). Factors influencing the self-efficacy beliefs of first year engineering students. Journal of Engineering Education, 95(1), 39 - 48.

18. Hackett, G., Betz, N.E., Casas, J.M., \& Rocha-Singh, I.A. (1992). Gender, ethnicity, and social cognitive factors predicting the academic achievement of students in engineering. Journal of Counseling Psychology, $39,527-538$.

19. Meinholdt, C. \& Murray, S. L. (1999). Why aren't there more women engineers? Journal of Women and Minorities in Science and Engineering, 5, 239-63.

20. Graham, S. (1994). Motivation in African Americans. Review of Educational Research, 64, 55 - 118.

21. Leslie, L.L., McClure, G. T. \&Oaxaca, R. L. (1998). Women and minorities in science and engineering: A life sequence analysis. The Journal of Higher Education, 69, 239-276.

22. Marra, R.M., Moore, C., Schuurman, M., \& Bogue, B. (2004). Assessing Women in Engineering (AWE): Assessment Women Engineering Students' Self-Efficacy Beliefs. Proceedings of the Annual meeting of the Women Engineering Program Advocacy Network, 2004. June 6 - 9, Albuquerque, N.M. Available at http://www.X-cd.com/wepan04/prof14.html.

23. Miller, D.C. (2002). Handbook of Research Design and Social Measurement. Thousand Oaks, CA.: Sage.

24. Felder, R., Felder, G., Mauney, M., Hamrin, C., \& Dietz, J. (1995). A longitudinal study of engineering student performance and retention. III. Gender differences in student performance and attitudes. Journal of Engineering Education, 84(2), 151-163.

25. Britner, S.L., Pajares, F. (2001). Self efficacy beliefs, motivation, race, and gender in middle school science. Journal of Women and Minorities in Science and Engineering, 7(4), $269-283$.

26. Reyes, M., Anderson-Rowland, M., \& McCartney, M. (1999). Student Success: What Factors Influence Persistence? Proceedings of the Annual Frontiers in Education Conference. San Juan, PR.

27. Malicky, D. A. (2003). Literature review on the under-representation of women in undergraduate engineering: Ability, self-efficacy, and the "chilly climate". Proceedings of the annual meeting of the American Society for Engineering Education Annual Conference, June 22-25, 2003. Retrieved December 15, 2006 from http://asee.org/acPapers/2003-1932_Final.pdf.

28. Strenta, A.C., Elliott, R., Adair, R. M., \& Scott, J. (1994). Choosing and leaving science in highly selective institutions. Research in Higher Education, 35, 513-47.

29. Goodman, I.F.; Cunningham, C.M.; Lachapelle, C.; Thompson, M.; Bittinger, K.; Brennan, R.T.; Delci,. M. (2002). Final report of Women's Experiences in College Engineering (WECE) project. Goodman Research Group Inc., Cambridge, MA. Available online at www.grginc.com.

30. Chubin, D.E. \& Babco, E. (2003). "Walking the talk" in Retention-to-Graduation: Institutional Production of Minority Engineers. Retrieved 26 February 2007 from www.nacme.org/pdf/WalkingTheTalk.pdf.

\section{Acknowledgements}


This research was made possible through grant \#0120642 from the National Science Foundation. Any opinions, findings, and conclusions or recommendations expressed in this material are those of the author(s) and do not necessarily reflect the views of the National Science Foundation.

We would also like to acknowledge the essential contributions of our AWE partners: Tricia Berry, Director of Women in Engineering at University of Texas - Austin; Brenda Hart Director of Student Affairs, Speed School of Engineering at the University of Louisville; Kathy Powel, at the University of Arizona. 